\title{
EFETIVIDADE DA FONOTERAPIA E PROPOSTA DE INTERVENÇÃO BREVE EM RESPIRADORES ORAIS
}

\section{Effectiveness of speech and language therapy and brief intervention proposal in mouth breathers}

\author{
Andréia Marson (1), Adriana Tessitore ${ }^{(2)}$, Eulália Sakano ${ }^{(3)}$, Kátia Nemr ${ }^{(4)}$
}

\begin{abstract}
RESUMO
Objetivos: verificar o efeito da intervenção fonoaudiológica em um grupo de respiradores orais e propor terapia fonoaudiológica mínima no tratamento da respiração oral. Método: estudo prospectivo longitudinal, casuística de 40 sujeitos respiradores orais tratados no Hospital das Clínicas - setor de Reabilitação Orofacial do Ambulatório de Respirador Oral da Disciplina de Otorrinolaringologia da Faculdade de Ciências Médicas da Universidade Estadual de Campinas - UNICAMP. Realizada documentação fotográfica, avaliação clínica, aplicação de protocolo para categorizar modo respiratório, postura (lábios e bochechas); força e praxias (lábios, bochechas e língua) nas semanas 0, 12 e 24. A proposta terapêutica constou de treino e conscientização da respiração nasal; manobras para aquecimento e vascularização da musculatura orofacial; aplicação de pontos e zonas motoras na face; manobras passivas; uso do impulso distal; exercícios miofuncionais e registro da percepção dos pacientes sobre suas condições olfativas e obstruções nasais. Teste estatístico: não paramétrico de Igualdade de Duas Proporções, $p<0,05$. Resultados: houve adequação da função respiração nasal. Aumento da força de lábios, língua e bochechas. Melhora nas praxias: bico direita, bico esquerda, estalo e vibração de lábios. Vibração e estalo de língua. Inflar simultaneamente as bochechas, inflar bochecha direita e esquerda. O tempo com maior ganho terapêutico foi de 12 semanas. A partir deste dado foi esquematizado protocolo com 12 sessões estruturadas abordando estratégias utilizadas nesta pesquisa. Conclusão: a pesquisa demonstrou que o uso da reabilitação miofuncional para pacientes respiradores orais foi eficiente com maior evolução terapêutica observada na semana 12.
\end{abstract}

DESCRITORES: Respiração Bucal; Criança; Fonoaudiologia; Reabilitação; Eficácia

\section{INTRODUÇÃO}

A respiração oral é uma alteração funcional caracterizada pelo uso da cavidade oral

(1) Fonoaudióloga; Aluna de Especialização em Motricidade Orofacial do Cefac, Aprimoramento em Fonoaudiologia Pediátrica pela Faculdade de Ciências Médicas da Universidade Estadual de Campinas.

(2) Fonoaudióloga; Responsável pelo Setor de Fonoaudiologia do Ambulatorio de Respiração Oral do HC/Unicamp; Mestre e Doutora em Ciências Médicas pela Faculdade de Ciências Médicas da Universidade Estadual de Campinas.

(3) Médica Otorrinolaringologista; Chefe do Ambulatório de Respiração Oral do Hospital das Clínicas da Universidade Estadual de Campinas; Doutora em Ciências Médicas pela Universidade Estadual de Campinas.

(4) Fonoaudióloga, Docente da Faculdade de Medicina da Universidade de São Paulo, Doutora em Psicologia Social pela Universidade de São Paulo.

Conflito de interesses: inexistente predominantemente na respiração e o desuso da cavidade nasal ${ }^{1-10}$. Pode ser consequência de um hábito ou obstrução nasal ocasionada por congestão da mucosa nasal e deformidades anatômicas das fossas nasais $5,10,11$.

Em relação ao modo, a respiração pode ser classificada em ${ }^{11}$ :

- Nasal: uso predominantemente da cavidade nasal.

- Oral: uso predominantemente da cavidade oral por obstrução nasal.

- Mista: oro/nasal, tanto pela cavidade nasal quando não há obstrução, quanto pela cavidade oral quando há presença de obstrução nasal.

No modo respiratório oral perde-se o papel protetor das cavidades paranasais, auriculares e das vias aéreas inferiores realizada pela respiração 
nasa| ${ }^{3,4}$. Além disso, a alteração de qualquer parte do complexo orofacial manifesta-se não apenas localmente, mas perturbando todo o equilíbrio do sistema orgânico ${ }^{11,12}$. Comumente estão associadas à respiração oral alterações otorrinolaringológicas, craniofaciais e dentárias, nos órgãos fonoarticulatórios, corporais e nas funções orais ${ }^{13-23}$.

Dentre as alterações no crescimento facial relacionadas à respiração oral têm-se o aumento vertical do terço inferior da face, o arco maxilar estreito, palato em ogiva, ângulo goníaco obtuso, má-oclusão (mordida aberta, dentes incisivos superiores em protrusão e mordida cruzada) bem como crescimento craniofacial vertical ${ }^{11}$.

As alterações dos órgãos fonoarticulatórios decorrentes à respiração oral são: hipotonia, hipotrofia e hipofunção dos músculos elevadores da mandíbula; alteração da força muscular de lábios e bochechas; tensão do músculo constritor da faringe e suprahióideos; lábio inferior evertido ou interposto entre os dentes; lábio superior curto ou retraído; lábios secos, fissurados e feridos com alteração da cor; alteração na posição habitual da língua com tendência à elevação de dorso e ápice rebaixado ou entre as arcadas; diminuição da pressão intra-oral; presença de movimentos primários de língua; alteração sensorial nos receptores intra-orais diminuindo a sensopercepção da cavidade oral e ângulo nasal mais obtuso 3,11,20,22.

São relatadas na literatura alterações corporais relacionadas à respiração oral como deformidades torácicas; musculatura abdominal flácida e distendida; olheiras com assimetria de posicionamento dos olhos, olhar cansado; alteração na posição da cabeça e pescoço com alteração compensatória na coluna vertebral; escápulas assimétricas; assimetria pélvica; rotação anterior de ombros comprimindo o tórax; joelhos para dentro e hiperestendidos e pés planos $3,11,19,20,21-23$.

Mastigação ineficiente; deglutição atípica e/ou adaptada; fala imprecisa e voz com hiper ou hiponasalidade são as alterações funcionais orais comumente relacionadas à respiração oral 2,5,9,10,11,13,15. Também são relatadas na literatura alterações nutricionais, comportamentais e dificuldades de aprendizagem ${ }^{2,3,14,16-19}$.

O diagnóstico da respiração oral é realizado pelo médico otorrinolaringologista e a conduta pode ser clínica, medicamentosa e/ou cirúrgica dependendo da causa da obstrução nasal.

A intervenção fonoaudiológica para o tratamento da respiração oral proposta neste estudo aborda quatro aspectos considerados importantes na readequação da função de respiração: conscientização e treino do modo respiratório; manobras passivas; exercícios miofuncionais e atividades dirigidas para a atenção/percepção do modo respiratório.

O diferencial desta proposta é o uso das manobras passivas: manipulações manuais na musculatura da face, sempre seguindo o sentido das fibras musculares, a utilização de forças corporais através do impulso distal e uso da estimulação das zonas e pontos motores da face.

Os objetivos deste estudo foram verificar o efeito da intervenção fonoaudiológica em um grupo de respiradores orais e realizar uma proposta de intervenção mínima no tratamento da respiração oral.

\section{MÉTODO}

O tipo de estudo realizado foi prospectivo longitudinal com duração de 24 semanas.

Todos os sujeitos que participaram desta pesquisa assinaram o termo de consentimento livre e esclarecido. foram:

Os critérios de inclusão do grupo estudado

(a) Diagnóstico otorrinolaringológico de respiração oral pós intervenção cirúrgica e/ou medicamentosa.

(b) Faixa etária entre 5-12 anos.

(c) Triagem fonoaudiológica que diagnosticasse alterações da motricidade orofacial.

(d) Não estar em atendimento terapêutico fonoaudiológico prévio.

O critério de exclusão foi:

(a) Não concordância em assinar Termo Consentimento Livre Esclarecido.

A casuística foi de 40 sujeitos respiradores orais tratados no Hospital das Clínicas - setor de Reabilitação Orofacial do Ambulatório de Respirador Oral da Disciplina de Otorrinolaringologia da Faculdade de Ciências Médicas da Universidade Estadual de Campinas - UNICAMP. Os atendimentos foram feitos uma vez por semana, durante 24 semanas, em todos os pacientes desta amostra. Como houve quatro desistências, os pacientes que definitivamente entraram na amostra foram 36 (Figura 1).

\section{I. $O$ modo respiratório foi avaliado por:}

- Uso de espelho de Glatzel: posicionado abaixo das narinas do paciente. O fluxo nasal ao entrar em contato com o espelho deixa-o embaçado. Com uma caneta foi traçada no espelho a marca deixada pela respiração nas semana 0 , semana12 e semana 24. Dessa forma utilizou-se o espelho de Glatzel para avaliar a aeração nasal do paciente. 


\begin{tabular}{|c|c|c|c|c|}
\hline $\mathbf{N}$ & Sexo & Idade & Alteração Otorrinolaringológica & Alteração Odontológica \\
\hline 1 & $\mathrm{~F}$ & 7 & - & Alteração Oclusão \\
\hline 2 & $\mathrm{~F}$ & 8 & - & - \\
\hline 3 & $\mathrm{~F}$ & 8 & - & Alteração Oclusão \\
\hline 4 & $\mathrm{M}$ & 7 & - & Alteração Oclusão \\
\hline 5 & $\mathrm{M}$ & 12 & - & - \\
\hline $6^{*}$ & $\mathrm{M}$ & 10 & - & - \\
\hline 7 & $\mathrm{M}$ & 7 & Rinite alérgica & - \\
\hline $8^{*}$ & $\mathrm{M}$ & 9 & - & - \\
\hline $9^{*}$ & $\mathrm{M}$ & 7 & - & - \\
\hline $10^{*}$ & $\mathrm{~F}$ & 5 & - & - \\
\hline 11 & $\mathrm{~F}$ & 12 & - & - \\
\hline 12 & $\mathrm{~F}$ & 12 & - & Alteração oclusão limitante para o vedamento labial \\
\hline 13 & $\mathrm{~F}$ & 5 & - & Alteração oclusão limitante para o vedamento labial \\
\hline 14 & $\mathrm{~F}$ & 5 & - & Alteração oclusão limitante para o vedamento labial \\
\hline 15 & $\mathrm{~F}$ & 12 & - & - \\
\hline 16 & M & 7 & - & - \\
\hline 17 & $\mathrm{M}$ & 12 & - & Alteração oclusão limitante para o vedamento labial \\
\hline 18 & $\mathrm{M}$ & 5 & - & - \\
\hline 19 & $\mathrm{~F}$ & 5 & - & - \\
\hline 20 & M & 11 & - & - \\
\hline 21 & $\mathrm{M}$ & 12 & - & Alteração oclusão limitante para o vedamento labial \\
\hline 22 & $\mathrm{M}$ & 6 & Rinite alérgica & - \\
\hline 23 & $\mathrm{M}$ & 12 & - & - \\
\hline 24 & $\mathrm{M}$ & 11 & - & - \\
\hline 25 & $\mathrm{M}$ & 5 & - & - \\
\hline 26 & $\mathrm{M}$ & 12 & - & - \\
\hline 27 & $\mathrm{M}$ & 12 & - & - \\
\hline 28 & $\mathrm{M}$ & 5 & - & - \\
\hline 29 & $\mathrm{~F}$ & 10 & - & - \\
\hline 30 & $\mathrm{~F}$ & 10 & - & Alteração oclusão limitante para o vedamento labial \\
\hline 31 & $\mathrm{~F}$ & 12 & - & - \\
\hline 32 & $\mathrm{~F}$ & 6 & - & - \\
\hline 33 & $\mathrm{M}$ & 12 & - & Alteração oclusão limitante para o vedamento labial \\
\hline 34 & $\mathrm{M}$ & 12 & - & Alteração oclusão limitante para o vedamento labial \\
\hline 35 & $\mathrm{M}$ & 6 & - & - \\
\hline 36 & $\mathrm{~F}$ & 12 & - & - \\
\hline 37 & $\mathrm{~F}$ & 11 & - & - \\
\hline 38 & $\mathrm{M}$ & 9 & Rinite alérgica & - \\
\hline 39 & $\mathrm{M}$ & 11 & Rinite alérgica & Hábito de sucção digital e Alteração dentária \\
\hline 40 & $\mathrm{~F}$ & 11 & Rinite alérgica & Alteração oclusão limitante para o vedamento labial \\
\hline
\end{tabular}

Legenda: N: número do caso; *: desistência/exclusão; F: feminino; M: masculino; -: nenhuma alteração digna de nota

Figura 1 - Caracterização do grupo em estudo

- Observação da função nasal durante a intervenção terapêutica, principalmente em atividades lúdicas e conversa espontânea.

- Avaliação funcional por meio do relato do paciente e seus pais, onde era questionado se em atividades cotidianas o paciente mantinha a respiração nasal.

\section{Avaliação dos aspectos morfológicos e posturais de lábios e bochechas:}

- Foi realizada documentação fotográfica do repouso facial nas semanas 0, 12 e 24 .
Utilizou-se câmera digital SAMSUNG, modelo Digimax S500. A câmera foi fixada a uma distância de $1,5 \mathrm{~m}$ do paciente, com luminosidade padronizada (mesmo ambiente). A centralização da fotografia foi realizada no terço médio da face do paciente. Foram utilizados os perfis lateral, frontal e ênfase na oclusão labial ${ }^{24}$.

- Para a avaliação da postura labial foram estabelecidas as seguintes categorias:
a) Abertos.
b) Entreabertos.
c) Vedados. 

d) Vedados com hipercontração do músculo mentual.

- Para a avaliação da postura de bochechas as categorias estabelecidas foram:
a) Simétricas.
b) Assimétricas.

Quando constatada assimetria houve correlação com a causa, classificada em assimetria por força (observada por meio da palpação de bochechas) ou assimetria por volume.

Cabe lembrar que a análise da posição habitual de língua não foi considerada neste estudo, pois estudos anteriores demonstraram que a inspeção clínica da posição habitual de língua é bastante subjetiva e sujeita à interpretações clínicas errôneas. Uma das formas objetivas de se avaliar a posição habitual da língua é a telerradiografia lateral com contraste de bário, não disponível para a realização deste estudo ${ }^{22}$.

\section{A avaliação da força de lábios, língua e bochechas.}

Realizada por meio da palpação manual da musculatura. No caso da língua, além da palpação foi posicionada espátula sobre a língua do paciente e solicitado o movimento de elevação.

As categorias estabelecidas para análise da força muscular foram:
a) Adequada
b) Aumentada
c) Diminuída

\section{Avaliação das praxias de lábios, língua e bochechas.}

Terapeuta solicitava com comando verbal e realizava a praxia como apoio visual para o paciente. Após observação categorizava o movimento.

As praxias solicitadas foram

a) Para lábios: bico fechado, sorriso fechado, bico esquerda, bico direita, estalo e vibração.

b) Para língua: lateralização, vibração, estalo, protrusão e retração.

c) Para bochechas: inflar simultaneamente, inflar direita e inflar esquerda.

Para a organização da coleta dos dados descritos nas avaliações acima foi confeccionado um protocolo (Figura 2) aplicado nas semanas 0 , 12 e 24 deste estudo.

Após a coleta de dados e registro no protocolo foi atribuído um escore para cada categoria analisada (Figura 2).

\section{Protocolo de reabilitação:}

O protocolo de reabilitação utilizado constou de:

a) Treino da conscientização da respiração nasal.

Uso de manobras orofaciais passivas propostas por Morales e Tessitore 11,12,25-27:

b) Exercícios miofuncionais.

c) Treino modo respiratório.

d) Treino tipo respiratório.

Para a conscientização da importância da respiração nasal foram utilizadas as seguintes estratégias:

- Orientação aos pais e pacientes sobre os cuidados com a higienização nasal e com a limpeza do ambiente em que vive o paciente. Explicação com figuras sobre a fisiologia normal da respiração e seus benefícios, bem como as consequências das alterações no modo e tipo respiratório na qualidade de vida do indivíduo.

- Leitura do livro "Dudu no mundo da Respiração" das autoras Ana Cristina Dias Netto e Renata Falótico Taborda, Pulso Editoral publicado em 2004.

- Higienização nasal: assoar cada narina separadamente. Utilizar $5 \mathrm{ml}$ aproximadamente de soro fisiológico na narina direita e solicitar que o paciente inspire. Massagear com o dedo indicador com movimentos circulares e assoar apenas a narina direita. Colocar mais $5 \mathrm{ml}$ na narina direita e repetir o procedimento.

Realizar todos os procedimentos acima descritos na narina esquerda.

Orientar realização de higiene nasal com soro fisiológico pelo menos duas vezes ao dia.

- Reforçar as orientações do tratamento otorrinolaringológico proposto para cada caso.

- No caso de pacientes com rinite alérgica, ressaltar os cuidados com a higiene do ambiente. Evitar acúmulo de poeira, bichos de pelúcia, mofo. Limpar o ambiente com hipoclorito diluído em água.

- Treino da percepção da movimentação corporal durante a respiração.

Solicitar que paciente coloque uma mão sobre a região do tórax e a outra sobre o abdômen e perceba o movimento da respiração.

- Treino da respiração diafragmática.

- Treino da respiração nasal: inspirar e expirar utilizando apenas uma narina. Inspirar e expirar lentamente. Inspirar e expirar rapidamente. Inspirar lentamente e expirar rapidamente. Inspirar rapidamente e expirar lentamente. A mudança no treino deverá ocorrer 
Iniciais:

Número Identificação:

Data:

Sessão: ( ) $0 \quad$ ( ) $12 \quad$ ( )24

\begin{tabular}{|c|c|c|}
\hline $\begin{array}{l}\text { Lábios: } \\
\text { Morfologia: } \\
\text { ( ) Abertos } \\
\text { ( ) Entreabertos } \\
\text { ( ) Vedados } \\
\text { ( ) Vedados com } \\
\text { hipercontração do músculo } \\
\text { mentual } \\
\text { Força Muscular: } \\
\text { ( ) Adequada } \\
\text { ( ) Aumentada } \\
\text { ( ) Diminuída } \\
\text { Praxias: } \\
\text { ( ) Bico fechado } \\
\text { ( ) Sorriso fechado } \\
\text { ( ) Bico direita } \\
\text { ( ) Bico esquerda } \\
\text { ( ) Estalo } \\
\text { ( ) Vibração }\end{array}$ & $\begin{array}{l}\text { Língua: } \\
\text { Força Muscular: } \\
\text { ( ) Adequada } \\
\text { ( ) Aumentada } \\
\text { ( ) Diminuída } \\
\text { Praxias: } \\
\text { ( ) Lateralização } \\
\text { ( ) Vibração } \\
\text { ( ) Estalo } \\
\text { ( ) Protrusão } \\
\text { ( ) Retração }\end{array}$ & $\begin{array}{l}\text { Bochechas: } \\
\text { Morfologia: } \\
\text { ( ) Simétricas } \\
\text { ( ) Assimétricas } \\
\text { Se assimétricas } \\
\text { por alteração de: } \\
\text { ( ) Força } \\
\text { ( ) Volume } \\
\text { Força Muscular: } \\
\text { ( ) Adequada } \\
\text { ( ) Aumentada } \\
\text { ( ) Diminuída } \\
\text { Praxias: } \\
\text { ( ) Inflar simultâneamente } \\
\text { ( ) Inflar direita } \\
\text { ( ) Inflar esquerda }\end{array}$ \\
\hline $\begin{array}{l}\text { Respiração: } \\
\text { ( ) oral } \\
\text { ( ) nasal } \\
\text { ( ) mista }\end{array}$ & $\begin{array}{l}\text { Observações em relação } \\
\text { condições odontológicas: }\end{array}$ & $\begin{array}{l}\text { Observações em relação } \\
\text { condições } \\
\text { otorrinolaringológicas: }\end{array}$ \\
\hline
\end{tabular}

Figura 2 - Ficha de Avaliação e Monitoramento Terapêutico

gradativamente de acordo com a dificuldade de cada paciente.

- Uso de Garrafas para exercícios respiratórios Pró-Fono para treino do modo respiratório: dentro de uma das garrafas colocou-se o volume inicial de $200 \mathrm{ml}$ de água. Solicitava-se que a criança inspirasse pelo nariz e na expiração soprasse o tubo plástico acoplado à garrafa com o objetivo de transferir a água de uma garrafa para outra. Aumentou-se o volume de água gradativamente até a medida de $450 \mathrm{ml}$ de acordo com o desempenho do paciente.

- Uso de bexiga: solicitava-se ao paciente que inspirasse 0 ar pelo nariz e na expiração soprasse enchendo a bexiga.
- Manutenção da respiração nasal com o vedamento labial: solicitava-se que o paciente respirasse pelo nariz ao mesmo tempo mantinha vedamento labial por meio do uso espátulas de madeira, elásticos ortodônticos, pedaços pequenos de gelatina incolor.

- Atividades lúdicas para verificar a manutenção da respiração nasal: pintura de desenhos, leitura de livros e jogos.

- Treino da respiração nasal em conversa expontânea monitorada: conversação expontânea onde era dito para o paciente os momentos em que realizou a respiração oral.

- Oposição respiração oral e nasal: solicitava-se que o paciente realizasse respiração oral e após nasal e descrevesse as diferenças percebidas. 
Utilização de manobras orofaciais propostas por Morales e Tessitore 11,12,25-27:

Com o paciente posicionado na maca, apoio de cunha na região cervical e de um rolo na região dos joelhos. As manobras utilizadas foram:

a) Manobras para aquecimento e vascularização:

1. Deslizar o dedo sobre o músculo frontal, com os dedos das mãos, no sentido encéfalo-caudal.

2. Com os dedos indicador e médio, a partir da articulação temporo mandibular (ATM), fazer movimentos descendentes até os lábios e voltar fazendo movimentos circulares novamente até a ATM. Fazer o mesmo da ATM até a comissura labial e depois até o queixo.

3. Tapping: na testa, com os dedos indicadores de cada mão, deslizar em movimentos pequenos, para cima e para baixo. Na face com o polegar e o dedo indicador, posição de pinça, soltar a musculatura com pequenas pressões.

4. Estímulo Somestésico:

4.1) Tocar com uma escova de dentes toda a face.

4.2) Ativação de pontos motores da face: os pontos motores são ramificações do nervo facial que mais se aproximam da pele. A estimulação atinge os pontos mais superficiais com o objetivo de contração muscular. Para ativação dos pontos motores era realizado dígito-pressão mais movimento circular. Os pontos utilizados estão demonstrados na figura $3^{11,12,20,25-27}$ :

\begin{tabular}{|c|c|c|c|c|c|}
\hline \multicolumn{2}{|c|}{ Respiração } & \multicolumn{2}{|l|}{ Lábios } & Língua & Bochechas \\
\hline \multicolumn{2}{|c|}{ Modo: } & \multicolumn{2}{|l|}{ Morfologia: } & Força: & Morfologia: \\
\hline Oral & (0) & Abertos & (0) & Diminuída & Simétricas $\quad \mathrm{S}(1) \mathrm{N}(0)$ \\
\hline Mista & (1) & Entreabertos & (1) & Aumentada & Se assimétricas: \\
\hline \multirow[t]{15}{*}{ Nasal } & $(2)$ & Vedados com hip. Mento & $(2)$ & Adequada & Força (1) \\
\hline & & Vedados & (3) & & Volume (0) \\
\hline & & Força: & & Praxias: & Força: \\
\hline & & Diminuída & (0) & Lateralização P(2) At (1) Au (0) & Diminuída \\
\hline & & Aumentada & (1) & Vibração $\quad P(2)$ At (1) Au (0) & Aumentada \\
\hline & & Adequada & (2) & $\mathrm{P}(2) \mathrm{At}(1) \mathrm{Au}(0)$ & Adequada \\
\hline & & & & Protrusão $\quad \mathrm{P}(2) \mathrm{At}(1) \mathrm{Au}(0)$ & \\
\hline & & & & Retração $\quad P(2)$ At (1) Au (0) & \\
\hline & & Praxias: & & & Praxias: \\
\hline & & Bico fechado $\quad P(2)$ At & At (1) Au (0) & & Inflar Sim $P(2)$ At (1) Au (0) \\
\hline & & Sorriso fechado $P(2) A t$ & At (1) Au (0) & & Inflar D $\quad \mathrm{P}(2)$ At (1) Au (0) \\
\hline & & $\mathrm{P}(2) \mathrm{At}$ & At (1) Au (0) & & Inflar $\mathrm{E} \quad \mathrm{P}(2)$ At (1) Au (0) \\
\hline & & $\mathrm{P}(2) \mathrm{At}$ & At (1) Au (0) & & \\
\hline & & $\mathrm{P}(2) \mathrm{At}$ & At (1) Au (0) & & \\
\hline & & Vibração & At (1) Au (0) & & \\
\hline
\end{tabular}

Legenda: hip: hipercontração; P: presente; At: alterado; Au: ausente; S: sim; N: não; Sim: simétrico; D: direita; E: esquerda

\section{Figura 3 - Caracterização dos escores atribuídos a cada categoria analisada no estudo}

4.3) Ativação de zonas motoras da face: são zonas de reação, a partir das quais se podem ativar respostas motoras de um músculo ou de uma cadeia muscular através de estímulos táteis e proprioceptivos. A ativação das zonas motoras pode ocorrer pelos movimentos de toque (ativa-se Disco sensor de Merkel), deslizamentos (ativa-se terminações nervosas das raízes dos pelos); tração (fuso neuromuscular e órgão tendinoso de golgi) e pressão/vibração (ativa-se os receptores de Meissner e Vater Pacini) ${ }^{28}$. A Figura 4 demonstra cada zona motora e seu respectivo sentido de estimulação. 


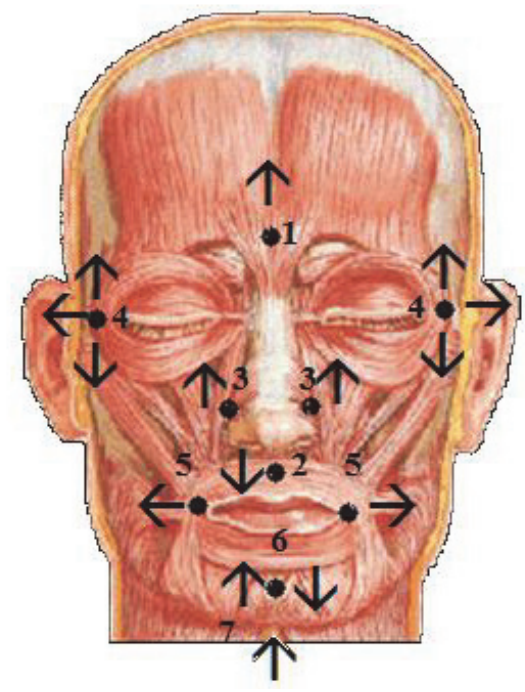

1. Zona nasal superior; 2. zona nasal inferior ou zona do lábio superior; 3. zona das asas do nariz; 4. zona da pálpebra; 5. zona do lábio; 6 . zona do mento; 7 . zona motora da língua ou do soalho da boca.

Fonte: TESSITORE, A. O uso da zona motora da língua como facilitadora da deglutição.. In: MARCHESAN, I. Q.. (Org.). Tratamento da deglutição. 1 ed. São José dos Campos: Pulso, 2005, v. 1 , p. $101-106$.

\section{Figura 4 - llustração das zonas motores da face com o sentido da estimulação}

b) Manobras de manipulação musculatura orofacial:

1. Fechar os quatro dedos de cada mão e com o polegar deslizar do queixo até a ATM, passando pelo queixo, comissura labial, músculo zigomático e canto externo do olho.

2. Deslizar com o polegar da comissura labial pelo feixe do músculo bucinador.

3. Com os dedos indicadores e médio em "V" deslizar partindo do centro do músculo orbicular da boca em direção ao músculo bucinador.

4. Colocar o dedo indicador logo abaixo do osso mandibular e pressionar. Cada vez que o paciente deglutir, soltar os dedos.

5. Com os dedos indicador e médio, fazer movimentos circulares na região das têmporas. Descer deslizando até o ângulo goníaco, subir para o feixe inclinado do músculo masseter até o arco zigomático $\mathrm{e}$ voltar deslizando até o ângulo goníaco.

6. Deslizar as palmas das mãos sobre as bochechas no sentido de baixo para cima.

7. Pedir ao paciente para elevar as sobranceIhas e segurar. Deslizar os dedos fazendo força contra o movimento da testa. Quando chegar no meio da testa, solicita-se ao paciente que solte a contração do músculo frontal e realizar contração nasal. Deslizar os dedos até o nariz. Quando chegar no nariz, pedir para o paciente soltar a contração nasal. Deslizar os dedos indicadores sobre os feixes do músculo piramidal até a região das narinas. Segurar as narinas abertas e solicitar que o paciente inspire e expire.

8. Manobra intraoral:com os dedos indicadores na cavidade oral, deslizar os dedos polegares sobre a face do paciente no sentido distal para medial, como se formasse um raio de sol. Após solicitar isometria do músculo bucinador.

Foram realizados exercícios miofuncionais para melhora do controle de força e mobilidade da musculatura orofacial $11,19,25-27,29,30$ :

a) Músculo orbicular da boca: protrusão dos lábios, protrusão dos lábios com abertura, morder lábios superior e inferior, vibração de lábios, lateralização de lábios ocluídos, alongamento labial superior e inferior, resistência a oclusão labial e pressionar os lábios e estalar.

b) Musculatura da língua: varrer palato com a ponta da língua, pressão da ponta da língua contra o palato, estalo da ponta da língua e estalo completo, elevação da ponta da língua até lábio superior, abaixamento da língua até lábio inferior, empurrar a língua contra a espátula, treino movimento de vibração, tocar com a ponta da língua último dente da arcada superior do lado direito e esquerdo.

c) Bochechas: inflar simultaneamente, inflar unilateralmente, inflar simultaneamente e terapeuta pressionar uma bochecha, encher bexiga.

A escolha do exercício miofuncional e do número de repetições foi adequada individualmente de acordo com a necessidade do paciente.

Como atividades dirigidas para o treino da percepção da função nasal, aqui considerada como a capacidade olfativa do nariz, e percepção das condições nasais (obstruções ou não, identificar qual a narina com maior facilidade para respirar) foram elaborados 2 diários, um para criança com escrita e outro para criança sem escrita, para que registrassem em seus domicílios cheiros mais marcantes, diferentes durante a semana bem como as condições nasais diariamente.

O projeto desta pesquisa recebeu parecer favorável do Comitê de Ética em Pesquisa da faculdade de Ciências Médicas da Universidade Estadual de Campinas, sob o parecer $n^{\circ}$ 624/2007. 
Para a análise dos dados coletados foi utilizado teste não paramétrico de Igualdade de Duas Proporções. Para cada comparação foi adotado p-valor com nível de significância de 0,05 (5\%).

\section{RESULTADOS}

Os pacientes distribuíram-se em 23 do sexo masculino e 17 do feminino. A média de idade foi de 9,8 anos. Três pacientes apresentavam alteração de oclusão com possibilidade de vedamento labial. Nove pacientes apresentavam alteração de oclusão com limitação para o vedamento labial. Cinco pacientes eram respiradores orais por etiologia de rinite alérgica.

\section{Respiração:}

Tabela 1 e tabela 5.

\section{Lábios:}

Tabela 2 e tabela 5.

\section{Língua:}

Tabela 3 e tabela 5.

\section{Bochechas:}

Tabela 4 e tabela 5.

Tabela 1 - Distribuição da amostra quanto a evolução do modo respiratório em números absolutos e percentuais

\begin{tabular}{lccc}
\hline Respiração & Sem 0 & Sem 12 & Sem 24 \\
\hline Mista & $0(0 \%)$ & $7(19,4 \%)$ & $5(13,9 \%)$ \\
Nasal & $0(0 \%)$ & $28(77,8 \%)$ & $31(86,1 \%)$ \\
Oral & $36(100 \%)$ & $1(2,8 \%)$ & $0(0,0 \%)$ \\
\hline
\end{tabular}

Legenda: sem $0=$ semana 0 sem $12=$ semana 12 sem $24=$ semana 24

Tabela 2 - Distribuição da amostra em relação à evolução das categorias de postura, força e praxias de lábios em números absolutos e percentuais

\begin{tabular}{|c|c|c|c|c|}
\hline Lábios & & Sem 0 & Sem 12 & Sem 24 \\
\hline \multirow{4}{*}{ Morfologia } & Abertos & $13(36,1 \%)$ & $(5,6 \%)$ & $(0 \%)$ \\
\hline & Entreabertos & $22(61,1 \%)$ & $10(27,8 \%)$ & $5(13,9 \%)$ \\
\hline & Vedados & $0(0 \%)$ & $15(41,7 \%)$ & $20(55,6 \%)$ \\
\hline & Hipercontração Mento & $1(2,8 \%)$ & $9(25 \%)$ & $11(30,6 \%)$ \\
\hline \multirow{2}{*}{ Força } & Adequada & $3(8,3 \%)$ & $28(77,8 \%)$ & $35(97,2 \%)$ \\
\hline & Diminuída & $33(91,7 \%)$ & $8(22,2 \%)$ & $1(2,8 \%)$ \\
\hline \multirow{2}{*}{ Bico Fechado } & Alterada & $2(5,6 \%)$ & $1(2,8 \%)$ & $1(2,8 \%)$ \\
\hline & Presente & $34(94,4 \%)$ & $35(97,2 \%)$ & $35(97,2 \%)$ \\
\hline \multirow{2}{*}{ Sorriso Fechado } & Alterada & $1(2,8 \%)$ & $0(0 \%)$ & $0(0 \%)$ \\
\hline & Presente & $34(94,4 \%)$ & $36(100 \%)$ & $36(100 \%)$ \\
\hline \multirow{2}{*}{ Bico Direita } & Alterada & $7(19,4 \%)$ & $(0 \%)$ & $0(0 \%)$ \\
\hline & Presente & $29(80,6 \%)$ & $36(100 \%)$ & $36(100 \%)$ \\
\hline \multirow{2}{*}{ Bico Esquerda } & Alterada & $7(19,4 \%)$ & $(0 \%)$ & $0(0 \%)$ \\
\hline & Presente & $29(80,6 \%)$ & $36(100 \%)$ & $36(100 \%)$ \\
\hline \multirow{2}{*}{ Estalo } & Alterada & $4(11,1 \%)$ & $0(0 \%)$ & $0(0 \%)$ \\
\hline & Presente & $32(88,9 \%)$ & $36(100 \%)$ & $36(100 \%)$ \\
\hline \multirow{3}{*}{ Vibração } & Alterada & $17(47,2 \%)$ & $5(13,9 \%)$ & $2(5,6 \%)$ \\
\hline & Ausente & $4(11,1 \%)$ & $1(2,8 \%)$ & $1(2,8 \%)$ \\
\hline & Presente & $15(41,7 \%)$ & $30(83,3 \%)$ & $33(91,7 \%)$ \\
\hline
\end{tabular}

Legenda: sem $0=$ semana 0 sem $12=$ semana 12

sem $24=$ semana 24 
Tabela 3 - Distribuição da amostra quanto à evolução das categorias da língua em números absolutos e percentuais

\begin{tabular}{llccc}
\hline Língua & & Sem 0 & Sem 12 & Sem 24 \\
\hline \multirow{2}{*}{ Força } & Adequada & $20(55,6 \%)$ & $34(94,4 \%)$ & $35(97,2 \%)$ \\
& Diminuída & $16(44,4 \%)$ & $2(5,6 \%)$ & $1(2,8 \%)$ \\
\hline \multirow{2}{*}{ Lateralização } & Presente & $36(100 \%)$ & $36(100 \%)$ & $36(100 \%)$ \\
\hline \multirow{2}{*}{ Vibração } & Alterada & $10(27,8 \%)$ & $0(0 \%)$ & $1(2,8 \%)$ \\
& Ausente & $6(16,7 \%)$ & $2(5,6 \%)$ & $1(2,8 \%)$ \\
& Presente & $20(55,6 \%)$ & $34(94,4 \%)$ & $34(94,4 \%)$ \\
\hline \multirow{2}{*}{ Estalo } & Alterada & $8(22,2 \%)$ & $2(5,6 \%)$ & $2(5,6 \%)$ \\
& Presente & $28(77,8 \%)$ & $34(94,4 \%)$ & $34(94,4 \%)$ \\
\hline Protrusão & Presente & $36(100 \%)$ & $36(100 \%)$ & $36(100 \%)$ \\
\hline Retração & Presente & $36(100 \%)$ & $36(100 \%)$ & $36(100 \%)$ \\
\hline
\end{tabular}

Legenda: sem $0=$ semana 0 sem $12=$ semana 12 sem $24=$ semana 24

Tabela 4 - Distribuição da amostra quanto à evolução das categorias para bochechas em números absolutos e percentuais

\begin{tabular}{llccc}
\hline Bochechas & & Sem 0 & Sem 12 & Sem 24 \\
\hline \multirow{2}{*}{ Simétricas } & Não & $18(50,0 \%)$ & $4(11,1 \%)$ & $1(2,8 \%)$ \\
& Sim & $18(50,0 \%)$ & $32(88,9 \%)$ & $35(97,2 \%)$ \\
\hline \multirow{2}{*}{ Assimetria } & NA & $18(50,0 \%)$ & $32(88,9 \%)$ & $35(97,2 \%)$ \\
& Não & $11(30,6 \%)$ & $3(8,3 \%)$ & $1(2,8 \%)$ \\
\hline \multirow{2}{*}{ Volumosas } & Sim & $7(19,4 \%)$ & $1(2,8 \%)$ & $0(0 \%)$ \\
\hline \multirow{2}{*}{ Força } & Não & $13(36,1 \%)$ & $18(50 \%)$ & $22(61,1 \%)$ \\
& Sim & $23(63,9 \%)$ & $18(50 \%)$ & $14(38,9 \%)$ \\
\hline \multirow{2}{*}{ InflarSim } & Adequada & $5(13,9 \%)$ & $28(77,8 \%)$ & $34(94,4 \%)$ \\
& Diminuída & $31(86,1 \%)$ & $8(22,2 \%)$ & $2(5,6 \%)$ \\
\hline \multirow{2}{*}{ InflarD } & Alterada & $4(11,1 \%)$ & $1(2,8 \%)$ & $0(0 \%)$ \\
& Presente & $32(88,9 \%)$ & $35(97,2 \%)$ & $36(100 \%)$ \\
\hline \multirow{2}{*}{ InflarE } & Alterada & $10(27,8 \%)$ & $1(2,8 \%)$ & $0(0 \%)$ \\
& Presente & $26(72,2 \%)$ & $35(97,2 \%)$ & $36(100 \%)$ \\
\hline
\end{tabular}

Legenda: sem $0=$ semana 0 sem $12=$ semana 12 sem $24=$ semana

Houve resultados estatisticamente significantes para:

- Adequação da função da respiração nasal.

- Adequação de força de lábios, língua e bochechas.

- Adequação nas praxias: bico direita, bico esquerda, estalo e vibração de lábios. Vibração e estalo de língua. Inflar simultaneamente as bochechas, inflar bochecha direita e inflar esquerda.

O conjunto de dados demonstra efetividade da proposta de reabilitação utilizada neste estudo.
Quanto ao fator tempo, notou-se que a maior evolução da terapia ocorreu até a semana 12. No período semana 12 até semana 24 não houve ganho, mas sim a estabilização dos resultados atingidos.

Portanto, o tempo de 12 semanas foi considerado como o mínimo necessário à intervenção fonoaudiológica em respiradores orais no grupo estudado. A partir deste dado foi esquematizado um protocolo com 12 sessões estruturadas, como demonstrado na Figura 5. 
Tabela 5 - Comparação das categorias analisadas por meio de p-valores nos intervalos de tempo pré-determinados

\begin{tabular}{lccc}
\hline Categoria Analisada & $\mathbf{0 - 1 2}$ & $\mathbf{0 - 2 4}$ & $\mathbf{1 2 - 2 4}$ \\
\hline Respiração oral & $0,001^{*}$ & $0,001^{*}$ & 0,314 \\
Respiração mista & $0,005^{*}$ & $0,020^{*}$ & 0,527 \\
Lábios abertos & $0,001^{*}$ & $<0,001^{*}$ & 0,151 \\
Lábios entreabertos & $0,004^{*}$ & $<0,001^{*}$ & 0,147 \\
Lábios vedados com contração mentual & $0,006^{*}$ & $0,002^{*}$ & 0,599 \\
Força labial adequada & $<0,001^{*}$ & $<0,001^{*}$ & $0,013^{*}$ \\
Praxia labial de vibração alterada & $0,002^{*}$ & $<0,001^{*}$ & 0,233 \\
Força lingual adequada & $<0,001^{*}$ & $<0,001^{*}$ & 0,555 \\
Praxia lingual de vibração ausente & $0,047^{*}$ & $<0,001^{*}$ & 0,555 \\
Praxia lingual de estalo alterada & $0,041^{*}$ & $0,041^{*}$ & 1,000 \\
Assimetria de bochechas & $0,024^{*}$ & $0,005^{*}$ & 0,314 \\
Força de bochechas adequada & $<0,001^{*}$ & $<0,001^{*}$ & $0,041^{*}$ \\
\hline
\end{tabular}

Legenda:

0 -12: intervalo entre a semana 0 até semana 12 do estudo

0 -12: intervalo entre a semana 0 até semana 24 do estudo

12-24: intervalo entre a semana 12 até semana 24 do estudo

Teste de Igualdade de Duas Proporções.

p-valor com nível de significância de 0,05 (5\%)

\section{DISCUSSÃO}

O conjunto de dados analisados neste estudo permitiu verificar eficácia na terapia fonoaudiológica utilizada na reabilitação da função de respiração.

Houve resultados estatisticamente significantes para a adequação do modo respiratório, da força de lábios, língua e bochechas, das praxias: bico direita, bico esquerda, estalo e vibração de lábios; vibração e estalo de língua; inflar simultaneamente as bochechas, inflar bochecha direita e inflar esquerda.

Os resultados aqui apresentados são promissores e abrangem uma nova abordagem para a respiração oral.

A partir deste dado foi esquematizado um protocolo com 12 sessões estruturadas abordando estratégias para treino e conscientização da respiração nasal, uso de manobras orofaciais, exercícios miofuncionais e atividades dirigidas à percepção olfativa e condições nasais.

Mesmo pacientes com limitações prognósticas na terapia fonoaudiológica, como rinite alérgica e oclusão dentária alterada limitante do vedamento labial demonstraram ter ganhado na função de respiração nasal e melhora de força e praxias das estruturas avaliadas dentro do tempo proposto. Provavelmente tais limitações repercutem nas funções orais de mastigação, deglutição e fala que não foram analisadas como categorias neste estudo $6,7,9,11,21,30$.
Estudos anteriores demonstraram que a terapia miofuncional breve pode proporcionar melhora na função de respiração, na postura de repouso e força de lábios ${ }^{11,27,28-31}$.

Entretanto, não existe na literatura um consenso sobre o tempo estipulado para o tratamento especificamente da respiração oral. Alguns estudos sobre a terapia miofuncional orofacial indicam 8 sessões como forma de intervenção breve. Os autores relatam que com este tempo obtiveram aumento da aeração nasal, adequação do vedamento e força labial e como consequência melhora na função respiratória. Entretanto, a casuística e a intervenção terapêutica dos estudos relatados diferem das utilizadas nesta pesquisa ${ }^{31,32-34}$.

Os resultados apresentados neste estudo apontam o tempo de 12 sessões como um estabilizador das categorias analisadas.

Para as categorias força de lábios e de bochechas houve resultado estatisticamente significante no intervalo sem12 para a sem24. Para os outros dados houve ganho até a semana 12, após este tempo não houve evolução significante, mas houve manutenção dos resultados atingidos.

Ainda sobre o tempo da terapia, não foram mensurados intervalos menores para verificar se antes da sessão 12, há estabilização dos resultados. Pretende-se em estudo posterior verificar a eficácia num tempo mínimo e para tanto serão realizados re-avaliações com menor periodicidade 


\begin{tabular}{|c|c|c|c|c|c|c|}
\hline Sessão & $\begin{array}{l}\text { Aplicação } \\
\text { Ficha de } \\
\text { Avaliação }\end{array}$ & Conscientização & $\begin{array}{l}\text { Manobras } \\
\text { Orofaciais }\end{array}$ & $\begin{array}{l}\text { Exercícios } \\
\text { Miofuncionais }\end{array}$ & Diário & $\begin{array}{l}\text { Documentação } \\
\text { Fotográfica }\end{array}$ \\
\hline 01 & Sim & $\begin{array}{l}\text { Seguir orientações corretas sobre } \\
\text { tratamento médico; } \\
\text { Treino higienização nasal; } \\
\text { Orientações sobre profilaxia ambiental; } \\
\text { Fisiologia Respiração (desenhos } \\
\text { ilustrativos). }\end{array}$ & & & & Sim \\
\hline 02 & & $\begin{array}{l}\text { Percepção movimentação corporal durante } \\
\text { a respiração; } \\
\text { Treino movimento "barriguinha-barrigão". } \\
\text { Inspirar e expirar utilizando uma narina por } \\
\text { vez; } \\
\text { Inspirar e expirar lentamente; } \\
\text { Inspirar e expirar rapidamente; } \\
\text { Inspirar lentamente e expirar rapidamente; } \\
\text { Inspirar rapidamente e expirar lentamente. } \\
\text { Graduar a dificuldade na execução dos } \\
\text { exercícios. }\end{array}$ & $\begin{array}{l}\text { Manobras para } \\
\text { aquecimento e } \\
\text { regulação da } \\
\text { musculatura } \\
\text { orofacial; } \\
\text { Aplicação de } \\
\text { Pontos e zonas } \\
\text { motoras da face; } \\
\text { Uso de apoios } \\
\text { corporais e } \\
\text { impulso distais } \\
\text { para aumento da } \\
\text { força muscular; }\end{array}$ & Sim & Sim & \\
\hline 03 & & $\begin{array}{l}\text { Uso de Garrafas para exercícios } \\
\text { respiratórios Pró-Fono }\end{array}$ & Idem sessão 2 & Sim & $\begin{array}{l}\text { Relatar cheiros } \\
\text { que gosta e que } \\
\text { não gosta } \\
\text { Diário Cheiros e } \\
\text { condições que } \\
\text { possibilitem a } \\
\text { respiração nasal }\end{array}$ & \\
\hline 04 & Sim & $\begin{array}{l}\text { Inspirar o ar pelo nariz e soprar enchendo } \\
\text { bexiga; }\end{array}$ & Idem sessão 2 & Sim & $\begin{array}{l}\text { Pintar desenho } \\
\text { mantendo } \\
\text { respiração nasal. } \\
\text { Diário Cheiros e } \\
\text { condições que } \\
\text { possibilitem a } \\
\text { respiração nasal }\end{array}$ & Sim \\
\hline 05 & & $\begin{array}{l}\text { Manter respiração Nasal com vedamento } \\
\text { labial segurando elástico no lábio. }\end{array}$ & Idem sessão 2 & Sim & $\begin{array}{l}\text { Diário Cheiros e } \\
\text { condições que } \\
\text { possibilitem a } \\
\text { respiração nasal }\end{array}$ & \\
\hline 06 & & $\begin{array}{l}\text { Manter respiração Nasal segurando palito; } \\
\text { Uso de Garrafas para exercícios } \\
\text { respiratórios Pró-Fono } \\
\text { Mudanças notadas pela criança com a } \\
\text { intervenção (antes e depois). }\end{array}$ & Idem sessão 2 & Sim & $\begin{array}{l}\text { Diário Cheiros e } \\
\text { condições que } \\
\text { possibilitem a } \\
\text { respiração nasal }\end{array}$ & \\
\hline 07 & & $\begin{array}{l}\text { Retomar exercícios sessão } 2 \text { + sessão } 3 \text { + } \\
\text { sessão } 4 . \\
\text { Graduar a difuldade na execução dos } \\
\text { exercícios. }\end{array}$ & Idem sessão 2 & Sim & $\begin{array}{l}\text { Diário Cheiros e } \\
\text { condições que } \\
\text { possibilitem a } \\
\text { respiração nasal }\end{array}$ & \\
\hline 08 & Sim & $\begin{array}{l}\text { Verificar predominância do modo } \\
\text { respiratório em contexto lúdico. }\end{array}$ & Idem sessão 2 & Sim & $\begin{array}{l}\text { Diário Cheiros e } \\
\text { condições que } \\
\text { possibilitem a } \\
\text { respiração nasal }\end{array}$ & Sim \\
\hline 09 & & Leitura mantendo respiração nasal & Idem sessão 2 & Sim & $\begin{array}{l}\text { Diário Cheiros e } \\
\text { condições que } \\
\text { possibilitem a } \\
\text { respiração nasal }\end{array}$ & \\
\hline 10 & & $\begin{array}{l}\text { Retomar exercícios sessão } 2 \text { + sessão } 3 \text { + } \\
\text { sessão } 4 \text { + sessão } 5 \text {. }\end{array}$ & Idem sessão 2 & $\operatorname{sim}$ & $\begin{array}{l}\text { Diário Cheiros e } \\
\text { condições que } \\
\text { possibilitem a } \\
\text { respiração nasal }\end{array}$ & \\
\hline 11 & & Respiração nasal em conversa monitorada. & Idem sessão 2 & Sim & $\begin{array}{l}\text { Diário Cheiros e } \\
\text { condições que } \\
\text { possibilitem a } \\
\text { respiração nasal }\end{array}$ & \\
\hline 12 & Sim & & & & $\begin{array}{l}\text { Diário Cheiros e } \\
\text { condições que } \\
\text { possibilitem a } \\
\text { respiração nasal }\end{array}$ & Sim \\
\hline
\end{tabular}

Figura 5 - Resumo intervenção 12 sessões

dentro deste tempo de 12 sessões que já mostrou ser eficaz.

$\mathrm{Na}$ amostra analisada mesmo os pacientes com alterações do crescimento facial foram beneficiados pela intervenção atingindo o objetivo de respiração com o modo predominantemente nasal. Os casos associados à rinite alérgica mantiveram modo respiratório misto na semana 24 . A rinite alérgica 
já foi apontada por outros estudos como limitante na intervenção fonoaudiológica em respiradores orais $5,10,14,17$.

A alteração de praxias de língua mesmo na semana 24 foi associada na casuística estudada a manutenção de movimentos primários de língua. Estudo anterior aponta para maior frequência de manutenção dos movimentos primários de língua em um grupo de respiradores orais quando comparado a respiradores nasais ${ }^{35}$.

Baseado na estabilização dos resultados analisados é proposta a intervenção fonoaudiológica em respiradores orais no tempo de 12 semanas. A partir da técnica utilizada foram estruturadas 12 sessões.

Para cada sessão sugere-se atividades divididas em 4 objetivos que foram considerados neste estudo como fundamentais na adequação da respiração nasal. São eles:

- Treino e conscientização da respiração nasal;

- Manobras orofaciais da técnica proposta por Morales e por Tessitore ${ }^{11,12,27}$;

- Exercícios miofuncionais;

- Atividades dirigidas para percepção da função olfativa e condições nasais para a respiração.

O diferencial desta proposta é a técnica especifica para as manobras orofaciais. O trabalho através do toque diretamente na fibra muscular busca regular 0 tônus muscular. $O$ toque ativa receptores relacionados à percepção sensorial. A fibra muscular é estimulada pela percepção sensorial. Quando se trabalha com este protocolo atua-se diretamente com a fisiologia neuromuscular propriamente dita. Ativa-se a musculatura sempre respeitando o desenho e a ação do músculo estimulado, com o intuito de induzir o movimento passivamente. Associa-se a isto o uso do impulso distal, que é o uso da força das cadeias musculares como uma forma de facilitar e aumentar a força de contração da musculatura orofacial ${ }^{27}$.

A ativação das zonas e pontos motores da face também são recursos que estimulam os receptores subcutâneos e neuromusculares que geram respostas involuntárias que favorecem a recuperação sensorial e motora da musculatura. As zonas motoras da face são zonas de ação e reação a partir das quais as respostas de um músculo ou de um grupo muscular podem ser ativadas através de estímulos táteis e proprioceptivos. Estão localizadas nas intersecções dos músculos faciais.

Juntamente com a estimulação passiva são associados exercícios miofuncionais e recursos para o treino da respiração nasal no domicílio ${ }^{27}$.
Mesmo utilizando ficha de avaliação idêntica e coleta de dados padronizada, há limitações em analisar a eficácia da força de musculatura das estruturas avaliadas devido à subjetividade do método de avaliação clínica disponível. Alguns estudos vem sendo desenvolvidos na tentativa de objetivar tal avaliação por meio de recursos instrumentais como o sistema protótipo para medição das forças linguais em humanos e a avaliação com enfoque antroposcópico ${ }^{36-38}$.

O protocolo de reabilitação composto de conscientização nasal, manobras orofaciais passivas, exercícios miofuncionais e atividades dirigidas para a percepção olfativa e condições de respiração.

A melhora no modo respiratório, postura, força muscular e praxias das estruturas orofaciais analisadas neste estudo comprovam a eficácia do protocolo de reabilitação utilizado. Um fato a destacar, apesar das limitações em alguns sujeitos referentes às condições odontológicas e otorrinolaringológicas (rinite alérgica) houve ganho terapêutico, principalmente no modo respiratório.

Considera-se algumas limitações na metodologia utilizada neste estudo como forma de avaliar a eficácia da terapia utilizada, devido a própria subjetividade clínica dos procedimentos disponíveis atualmente para avaliação e monitoramento terapêutico. Estudos anteriores já trazem esta questão, pois a terapia fonoaudiológica é baseada numa abordagem integrada e envolve um grande número de intervenções em diversos grupos musculares. Dessa forma este método não permite determinar os efeitos de cada exercício específico no resultado geral. Por outro lado, essa pergunta nos parece pouco relevante visto que o tratamento de fato pressupõe a função de respiração como complexa e que uma abordagem fragmentada ou dirigida a um único aspecto está fadada ao insucesso.

Outra limitação a se considerar é que a generalização deste método deve ser vista com cuidado, pois o uso adequado dependerá de profissionais especializados.

\section{CONCLUSÃO}

O conjunto de dados demonstrou efetividade da proposta de reabilitação utilizada neste estudo.

O tempo com maior ganho terapêutico foi de 12 semanas. E, portanto, considerado como o menor tempo necessário à intervenção fonoaudiológica em respiradores orais no grupo estudado. 


\section{ABSTRACT}

Purposes: to check the effect of speech and language therapy on a group of mouth breathers, as well proposing a minimum therapy for mouth breathing treatment. Method: longitudinal prospective study, casuistic on 40 mouth breather subjects who were patients from the Otorhinolaryngology Ambulatory of UNICAMP Hospital. On weeks 0, 12 and 24, we proceeded photographical documentation, clinical assessment, and protocol application in order to categorize the breathing mode, posture (lips and cheeks), strength and movement (lips, cheeks and tongue). The applied therapeutic proposal consisted of practicing and awareness on nasal breathing; maneuvers to warm and vascularize the orofacial muscles; application of points and motor zones on the face; passive maneuvers; use of distal impulse; myofunctional exercises and register of patients' perception on their olfactive conditions and nasal obstructions. A non-parametric two proportion equality test was used, $p<0.05$. Results: nasal breathing function was adjusted. Increase on lip, tongue and cheek strength. Improvement on the movement: lips pouted to the right and left, snap and lip vibration. Vibration and snap of tongue. Simultaneous inflation of the cheeks, inflation of left and right cheeks alternately. The highest therapeutic gain occurred on 12 weeks. From such data it was possible to come up a protocol made up of 12 structured sessions using the strategies from this study. Conclusion: the study has demonstrated the effectiveness of using myofunctional rehabilitation for mouth breathers, and the highest therapeutic evolution took place during the $12^{\text {th }}$ week.

KEYWORDS: Mouth Breathing; Child; Speech, Language, Hearing Sciences; Rehabilitation; Efficacy

\section{REFERÊNCIAS}

1. Andrade LP, Majolo MS. A influência da respiração bucal no crescimento facial. Rev Goian Ortod. 2000; 5:34-45.

2. Queluz DP, Gimenez CMM. A síndrome do respirador bucal. Rev CROMG. 2000; 6(1): 4-9.

3. Marchesan IQ. A equipe de trabalho no respirador oral. In: Krakauer LH, Di Francesco RC, Marchesan $I Q$, organizadoras. Conhecimentos essenciais para entender bem a respiração oral. São José dos Campos: Pulso; 2003. p.163-7.

4. Frasson JMD, Borges MBA, Nouer DF, Siqueira VC, Lunardis N. Estudo cefalométrico comparativo entre respiradores nasais e predominantemente bucais. Rev Bras Otorrinolaringol. 2006;72(1):72-82.

5. Branco A, Ferrari GF, Weber SAT. Alterações orofaciais em doenças alérgicas de vias aéreas. Rev Paul Pediatr. 2007;25(3):266-70.

6. Bianchini AP, Guedes ZCF, Vieira MM. Estudo da relação entre a respiração oral e o tipo facial. Rev. Bras. Otorrinolaringol. 2007;73(4):500-5.

7. Bianchini AP, Guedes ZCF, Hitos S. Respiração oral: causa x audição. Rev CEFAC. 2009; 11(suppl.1):38-43.

8. Peltomäki T. The effect of mode of breathing on craniofacial growth-revisited. Eur $\mathrm{J}$ Orthod. 2007;29(5):426-9.

9. Pereira AC, Jorge TM, Ribeiro JPD, BerretinFelix G. Características das funções orais de indivíduos com má oclusão Classe III e diferentes tipos faciais. Rev Dent Press Ortodon Ortop Facial. 2005;10(6):111-9.

10. Lemos CM, Wilhelmsen NSW, Mion OG, Mello JJF. Alterações funcionais do sistema estomatognático em pacientes com rinite alérgica: estudo caso-controle. Rev Bras Otorrinolaringol. 2009;75(2):268-74.

11. Tessitore A. Alterações oromiofuncionais em respiradores orais. In: Ferreira LP, Befi-Lopes DM, Limongi SCO, organizadores. Tratado de Fonoaudiologia. São Paulo: Roca, 2004. p.261-76.

12. Castillo-Morales R. Técnicas da terapia. In: Castillo-Morales R. Terapia de Regulação orofacial. São Paulo: Memnon; 1999.p. 121-4.

13. Almeida FL, Silva AMT, Serpa EO. Relação entre má oclusão e hábitos em respiradores orais. Rev CEFAC 2009;11(1):86-93.

14. DiFrancesco RC, Passerotii G, Paulucci B, Miniti A. Respiração oral na criança: repercussões diferentes de acordo com o diagnóstico. Rev Bras Otorrinolaringol. 2004;70(5):665-70.

15. Tavares JG, Silva EHAA. Considerações teóricas sobre a relação entre respiração oral e disfonia. Rev Soc Bras Fonoaudiol. 2008;13(4):405-10.

16. Cunha DA, Silva GA, Motta MEFA, Lima CR, Silva HJ. A respiração oral em crianças e suas repercussões no estado nutricional. Rev. CEFAC. 2007;9(1):47-54. 
17. Campanha SMA, Freire LMS, Fontes MJF. O impacto da asma, da rinite alérgica e da respiração oral na qualidade de vida de crianças e adolescentes. Rev CEFAC. 2008;10(4):513-9.

18. Vera CFD, Conde GES, Wajnsztejn R, Nemr $\mathrm{K}$. Transtornos de aprendizagem em presença de respiração oral em indivíduos com diagnóstico de transtornos de déficit de atenção/hiperatividade (TDAH). Rev CEFAC. 2006;8(4): 441-55.

19. Marchesan IQ. Fundamentos em fonoaudiologia: aspectos clínicos da motricidade oral. Rio de Janeiro: Guanabara Koogan; 1998. Capítulo 4, Avaliação terapia dos problemas da respiração; $p$. 23-36.

20. Tessitore A. Intervenção fonoaudiológica breve junto à odontologia. In: Sociedade Brasileira de Fonoaudiologia, organizadora. Fonoaudiologia hoje. Collectanea Symposium - Série Medicina \& Saúde. São Paulo: Frôntis; 1998. p. 111-20.

21. Junqueira $P$. Avaliação e Diagnóstico Fonoaudiológico em Motricidade Oral. In: Ferreira LP, Befi-Lopes DM, Limongi SCO, organizadores. Tratado de Fonoaudiologia. São Paulo: Roca, 2004. Cap, 20, p. 230-6.

22. Tessitore A, Crespo NA. Análise radiográfica da posição habitual de repouso da língua. Pró Fono Rev Atual Cient. 2002; 14(1):7-16.

23. Rocabado Seaton M. Cabeza y cuello: tratamento articular. Buenos Aires. Inter-Médica Editorial, 1979.

24. Silveira MC, Tessitore A, Sigolo C. Proposta de documentação fotográfica em motricidade oral. Rev CEFAC. 2006; 8(4):485-92.

25. Tessitore A. Abordagem mioterápica com estimulação em pontos motores. In: Marquesan IQ, Zorzi JL, organizadores. Tópicos em fonoaudiologia. São Paulo: Lovise; 1995. p.75-82.

26. Tessitore A. O uso da zona motora da língua como facilitadora da deglutição. In: Marchesan IQ, organizador. Tratamento da deglutição. São José dos Campos: Pulso; 2005. p.101-6.

27. Tessitore A, Paschoal JR, Pfeilsticker LN. Avaliação de um protocolo da reabilitação orofacial na paralisia facial periférica. Revista CEFAC, 2009;11(3):432-40.

28. Douglas CR. Tratado de fisiologia aplicado a fonoaudiologia. São Paulo: Robe; 2002b. Fisiologia geral do sistema estomatognático e sensibilidade proprioceptiva estomatognática; p.289-314.

29. Degan VV, Puppin-Rontani RM. Aumento da aeração nasal após remoção de hábitos de sucção e terapia miofuncional. Rev CEFAC. 2007;9 (1):55-60.

30. Rahal A, Krakauer LH. Evaluation and speech therapy on mouth breathers. Rev Dent Press Ortodon Ortop Maxilar. 2001;6(1):83-6.

31. Bacha SMC, Ríspoli CF. Myofunctional therapy: brief intervention. Int J Orofacial Myology. 1999; 25:37- 47.

32. Marchesan IQ. The speech pathology treatment with alterations of the stomatognathic system. Int $\mathrm{J}$ Orof Myol. 2000;26:5-12.

33. Coutrin GC, Guedes LU, Motta AR. Treinamento muscular na face: a prática dos fonoaudiólogos de Belo Horizonte. Rev Soc Bras Fonoaudiol. 2008;13 (2):127-35.

34. Silva LMP, Aureliano FTS, Motta AR. Atuação fonoaudiológica na síndrome da apnéia e hipopnéia obstrutiva do sono: relato de caso. Rev CEFAC. 2007; 9(4):490-6.

35. Sigolo C, Silveira MC, Quintal M, Sakano E, Tessitore A. Ocorrência de movimentos primários de língua em crianças respiradoras oronasais. Revista CEFAC, 2008;10(1):51-7.

36. Perilo TCC, Motta AR, Las Casas EB, Saffar JME, Costa CG. Avaliação objetiva das forças axiais produzidas pela língua de crianças respiradoras orais. Rev Soc Bras Fonoaudiol. 2007;12(3):184-90. 37. Barroso MFS. Desenvolvimento de um sistema protótipo para medição objetiva das forças linguais em humanos. Sba Controle \& Automação.2009;20 (2):156-63.

38. Cattoni DM, Fernandes FD, Di Francesco RC. Características do sistema estomatognático de crianças respiradoras orais: enfoqueantroposcópico. Pró-Fono Rev Atual Cient. 2007;19(4):347-51.

http://dx.doi.org/10.1590/S1516-18462012005000054

RECEBIDO EM: 19/08/2011

ACEITO EM: 06/11/2011

Endereço para correspondência:

Andréia Marson

Avenida Paulo Cuba de Souza, 1490 -

Jardim Bom Sucesso

Campinas - SP

CEP: $13045-250$

E-mail: marson.andreia@gmail.com 